\title{
Evaluating the Potential of Virtual Simulations to Facilitate Professional Learning in Law: A Literature Review
}

\author{
Ann Thanaraj, ${ }^{1, *}$ \\ ${ }^{1}$ Uni of Cumbria, UK \\ *Correspondence: Uni of Cumbria, UK. E-mail: sunshineandchocolate@hotmail.co.uk
}

Received: November 20, 2016

Accepted: December 6, 2016 Online Published: December 23, 2016

doi:10.5430/wje.v6n6p89

URL: http://dx.doi.org/10.5430/wje.v6n6p89

\begin{abstract}
The use of virtual simulations in Legal Education as a method for learning is relatively rare despite much theoretical support that exists for the benefits in learning. There is also some apprehension on the use of technology in legal education. Both of these are likely due to the lack of solid evaluations concerning the overall impact in professional learning. The paper explores a number of possible theoretical frameworks which can be used in the design of the virtual law clinic simulation training programme and concludes that simulations can be used in professional learning through the experiential, immersive and active learning frameworks which effortlessly support Legal Education.
\end{abstract}

Keywords: learning development; virtual simulation; legal education; immersive learning; problem-based learning; situated learning; expansive learning; professional development, skills and identity

\section{Introduction}

Following on from the practice report which detailed the development and use of a virtual law clinic (VLC) in 2015 (Thanaraj \& Sales 2015), this paper reports on the literature review undertaken to further develop the VLC as a learning and training simulation for students, prior being used as a virtual clinic for undertaking actual client work online.

In order to design the training adequately, it is useful to undertake a review of the literature on the development and use of immersive learning through virtual simulations in the context of professional learning within Higher Education, and specifically in legal education. It will help to understand effective design of a technique to amplify real lawyering experiences with evoke substantial aspects of the real world in an interactive manner, used as a learning tool within the context of professional practice in law.

The rationale for using a virtual simulation in legal education is encompassed in the report by The Carnegie Foundation for the Advancement of Teaching entitled 'Educating Lawyers: Preparation for the Profession of Law' ('Carnegie Report') which makes the case that law schools fail to motivate students to consider their professional identity and social and ethical values (Cunningham \& Alexander, 2011). Traditionally, Legal Education focuses exclusively on doctrine and analytical skills rather than on professional learning (p.132-133). Specifically, the Carnegie Report suggests that by enabling students 'to encounter appealing representations of professional ideals, connect in a powerful way with engaging models of ethical commitment within the profession, and reflect on their own emerging professional identity in relation to those ideals and models' (p.134) law schools will be able to integrate 'student learning of theoretical and practical legal knowledge and professional identity' (p.13)

Therefore, this paper seeks to explore the evidence for the effectiveness of virtual simulations as a method for integrating professional learning. Garrison and Anderson (2003) support virtual simulations as an 'essential tool in creating rich and situated problem spaces' compatible with deep and meaningful approaches to learning' for learners to investigate and solve 'meaningful, real-world problems'(p.17). The paper takes forward the discussion on the effectiveness of simulations in developing professional skills awareness both within law and in a variety of employment settings. It concludes with a reflection on how simulations can be used in teaching. 


\section{Research Motivation}

The virtual simulation platform which was used to create the VLC (reported in 2015 in the International Journal of Clinical Legal Education) is also being used as a tool for training prior to students embarking on digital practice of law under supervision. The training sought to embed some of motivations of Clinical Legal Education into our training such as students having to demonstrate new knowledge and deeper understanding of law through solving problems for the clients; to demonstrate how to resolve legal issues; and to exercise appropriate level of judgement in resolving problems for clients (Thanaraj, 2016). It is hoped that students will gain a realistic view of the future of legal services and the profession and an understanding of the role of technology, privacy and security and how it affects legal ethics and constrains associated with this, whilst maintaining personal responsibility and accountability in both personal and group contexts online, working effectively with others online and undertaking decision-making in complex contexts.

Importantly, it is intended that students will become aware of representing the client in a manner that is consistent with the rules of the profession, especially in establishing a lawyer-client relationship online, understanding and working with online practice management systems, safe handling of data and the interpretation and implementation of professional conduct rules within an online law clinic.

\section{Research Focus}

In order to design the training adequately, there is emphasis on the importance of underpinning simulations with suitable theoretical frameworks (Kebritchi \& Hirumi, 2008). This literature review is organized into three areas of focus:

- A review of the theoretical frameworks wh i ch exist to support the use of virtual simulations in professional learning

- A snapshot of the evidence which exist to support claims of effective learning through virtual simulation within professional disciplines

- A reflection on the future directions on the practices of virtual simulations for future use in legal education

The literature was gathered from databases such as LexisNexis, Westlaw, HeinOnline, SSRN and Legal Journals Index, using the following keywords: legal education simulation; virtual simulation; digital simulations; immersive learning; experiential learning; digital legal education; virtual law clinics; legal education technology. In this literature review, the researcher takes a constructivist view to interpret and construct knowledge through the interpretation of interaction shaped by active experiences of social conditioning formed through network of relationships (Glasersfeld 1995, p.7).

In giving context to this paper and the researcher's interpretation, a simulation has been construed as any experiential activity which places students "within a reasonable representation of a real environment within which...interactions occur" (Krain and Shadle 2006, p 52) which involves an aspect of legal knowledge or practice for educational purpose, requiring students to determine how they would respond in a practical manner within a given situation (Shaw 2010). Although simulations can take place in the classroom, this paper investigates the use, design and implementation of a virtual/online simulated platform, however, it must be noted that the use of everyday technology such as word processing, fax and emails will be disregarded for the purposes of this review. This review builds on the results of a number of previous reviews that have been carried, in particular, within Legal Education.

\section{Identifying the Theoretical Frameworks Which Support the Use of Virtual Simulations}

\subsection{Situated Learning}

Prensky (2001) and Van Eck (2006), pioneers of situated learning, explain that effective learning taking place in a social context, usually embedded within an activity which requires the learner to acquire and apply conceptual knowledge in real-life, authentic situations. The principles of situated learning theory advocated by Lave and Wenger (1991) regard learning 'as a transaction between the person and the social environment' and may not necessarily refer to physical spaces, but to 'constructs of the person's experience in the social environment' (p. 200). Therefore, situated learning offers a practical emphasis where the learning of knowledge is integrated with the procedural application of the knowledge learnt. As such, virtual simulations have the potential to lend themselves well to facilitate engaging and immersive learning opportunities within a virtual 'community of practice' without the 
barriers and risks of the real world.

However, it can be challenging to design a virtual simulation as a learning methodology based on the situated learning framework. For example, the activities in the simulation will need to be designed as closely and as similarly to both real life situation and to situations which learners can relate to. It is important to balance these priorities so that students will be able to transfer knowledge from the virtual world setting to that of its actual application in professional settings.

Further, learners will need to be given a number of varied opportunities to practice skills such as problem solving, critical thinking and decision-making in order to make their learning meaningful, relevant and capable of transfer and application of knowledge (Ormrod, 1999; Anderson et al., 1996). There is also a need to embed an element of reflection which could be structured to address the matter of effective transfer of knowledge, analysing the activities undertaken in the simulation with the way it would work in real life Pivec, 2007).

\subsection{Experiential Learning}

Experiential learning is 'the process whereby knowledge is created through the transformation of experience' (Kolb, 1984, p. 41), beginning with a concrete experience, the learner observes and reflects upon the experience. Using these reflections, it may be possible to generalize how these reflections and new understanding can be utilized, with future experiences providing opportunities to test these generalizations.

Simulations have the flexibility to be designed in a manner which facilitates opportunities for immersive learning, applying existing knowledge and collaborative learning, whilst offering the opportunity to learning from errors without the actual consequence of the mistakes (Beard \& Wilson, 2002).

However, designing a virtual simulation which is capable of replicating authentic professional experience underpin by experiential learning pedagogy is challenging (Barab et al., 2000). As such, getting the balance right between designing activities at the appropriate level of learning and to maximizing learning and motivation with support can be a challenge, whilst maintaining the appropriate level of new learning and development for the learner (Csikszentmihalyi, 1990).

The construction of professional learning through active and immersive learning theory were developed further by De Freitas and Oliver (2006) focusing upon the four dimensions: context, learner, representation of the game and the underlying pedagogy. The success of learning is becoming when the learner takes on the role of an active participant in the learning processes, for example, sharing knowledge with other participants, working collaboratively and socially, creating knowledge and having control over the decisions and judgements they make within each activity. This experience and the consequential feedback gained from applying existing and new knowledge in practice allows simulations to be used as an effective platform for professional learning.

\subsection{Expansive Learning through Activity Theory}

Activity theory places emphasis upon the social interaction of learning that takes place within professional settings (Engestrom 1999; Vygotsky 1978; Leont'ev 1978, 1981). Learning which is designed using activity theory has the potential to bring about change in the way one conducts their working practices because of the challenges, tensions, influences and contradictions which could emulate real life situations, which offer different conceptions of learning and different views of professional practice (Engestrom 1999). Awareness of challenges in professional practice can be addressed by way of an expansive learning process (Figure 1) which encourages rethinking and consideration of professional learning, skills and ways of working (Engeström 2001)

Within the context of professional education, the process of expansive learning which brings about rethinking ways of practice and consequently a change in practice, the learner has the opportunity to construct their personal identity, understanding in professional ethics and values. Given that simulations are very effective learning techniques to raise awareness of a profession, its challenges and values (McClarty, Orr, Frey, Dolan, McVay and Vassileva, 2012), it is within this environment where students may begin to acquire the skills of decision-making, making judgment, develop an understanding fiduciary duties, effective communication, identifying ethical issues, using the law justly and fairly (Noone and Dickson, 2001) and exercising autonomy through an independent and self-directed manner (Hyams, 2008. Further, simulations are capable of fostering '...higher-order thinking skills such as planning and reasoning more than specific content knowledge' (Ke, 2009). 


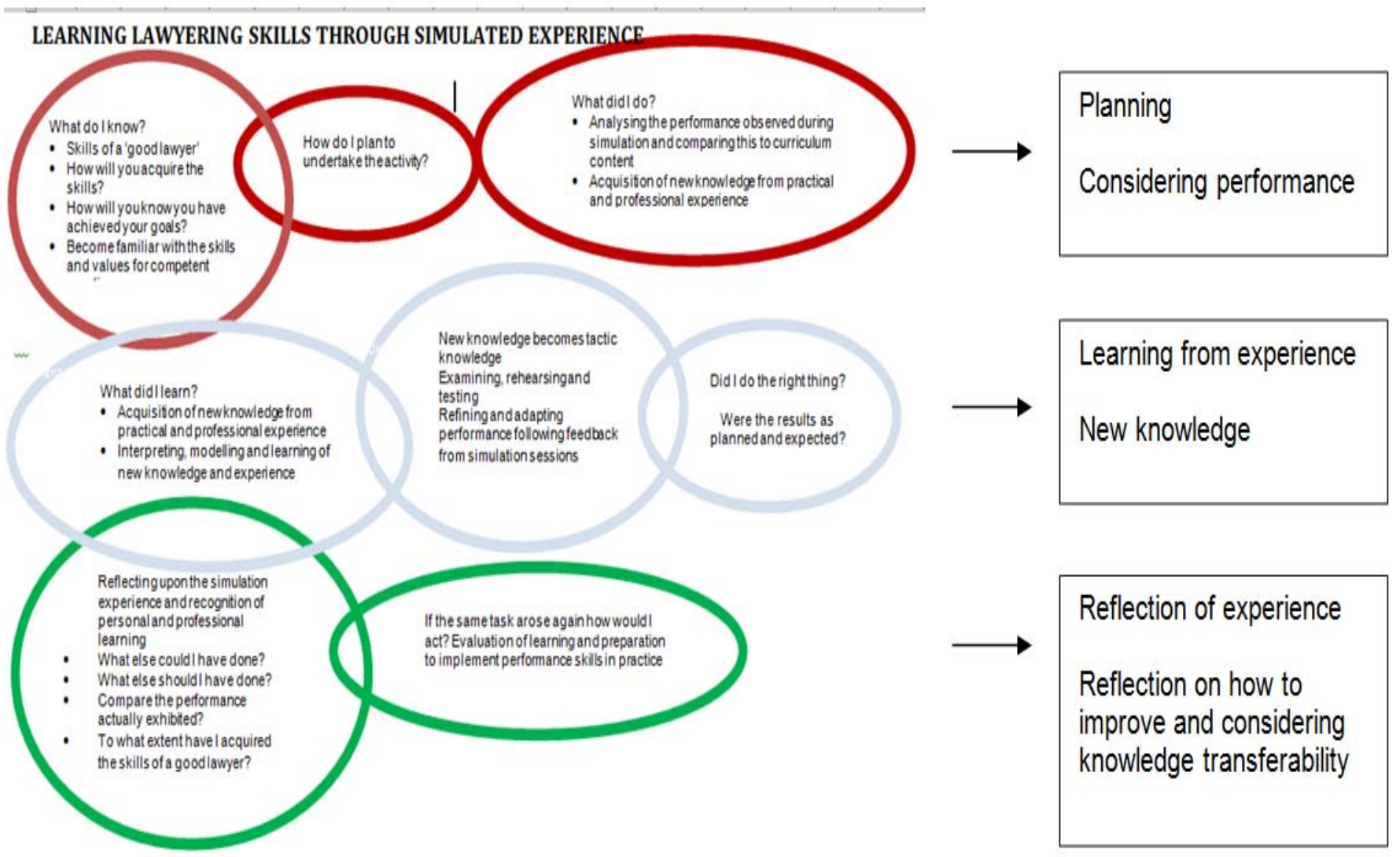

Figure 1. An Expansive Learning Method of Learning Lawyering and Professional Skills by Way of a Simulation

\subsection{Deep, Immersive and Reflective Learning}

According to Marton and Säljö (1976) and Laurillard (1993) effective deep learning takes place when students are able to interact with the task at hand and the environment within which the task is situated in. Students' perception of a task, its aims, its level of challenge and the interaction they have with the task can vary from one task to another. In this sense, it is argued that by learning using simulation technique, students become embedded into the activity, immersed in undertaking a solution to the problem at hand, facilitating, problem-solving, decision-making and understanding of how this process is relevant in professional settings. In this regard, simulations, if designed carefully with this intention, have the potential to raise awareness of professional identity, professional practices and an understanding of real work-based situations.

Simulations can offer a platform to utilize existing knowledge in practical situations (Greenblat 1973; Pierfy 1977; Morgan 2003), bringing about deeper learning through careful construction of how leaning is developed and applied and by allowing the learner to turn significant facts and principles remembered into meaningful new ways of applying it, connect it in appropriate situations and generate new solutions to problems (Smith and Boyer 1996). Students will also be able to gauge their own performance, supported by way of debriefing sessions, prompt feedback opportunities from tutors and peers and improved reflective learning practices build on those already undertaken throughout the students' learning.

\subsection{Problem-Based Learning}

The premise of PBL is built on a number of factors which create optimal learning for students. Problem-based learning (PBL) is a framework which offers relevant and realistic problem scenarios for learners to develop problem solving skills through real-world scenarios which serve as a springboard for understanding the impact these problems can have in actual work related settings (Gallagher, 1997; Reynolds, 1997). The environment in which PBL takes place is one that is designed to be immersive and practical with built-in feedback from peers and tutor. Ongoing activities are supported by guidance, discussion and collaboration between learners, tutors, knowledge recall, application of existing knowledge and developing new knowledge. New learning takes place at multiple levels 
because of the variety of interactions taking place in groups through cooperative learning and collaborative problem solving.

Apart from the active and experiential learning by doing aspect of PBL, the opportunities offered by learning through the PBL method allows students to become aware of what they know (tacit knowledge) and building on tacit knowledge to identify and solve problems. Whilst building on tacit knowledge, learners will be able to identify gaps in their knowledge and understanding whilst reflecting on an action plan to acquire the knowledge needed (Gijselaers, 1996). As such, given its practical nature of activities exposure to immersion and experience, the premise of PBL frames itself well to learning by way of simulation.

In an online PBL environment, students will be able to work synchronously (in real time) or asynchronously (at a later time to their convenience). The way students work and collaborate online may affect the nature of how and process of what learning takes place. Asynchronous communication creates opportunity for reflective learning, careful thinking and well-constructed articulated reasoning. Similarly, synchronous communication will require students to be able to draw on their own experience and existing knowledge to apply to problems and new situations whilst make sense of the application and the new knowledge being developed (Mezirow, 1981). As such, the premise of learning collaboratively in PBL encourages higher cognitive development such as critique, reasoning and challenge.

However, there are still questions that need to be explored about the way in which problem scenarios are designed and the extent to which digital environments can be learner centered and learner driven. Further, the success of learning through a PBL framework lies in the effectiveness of team working. There is abundance of research on the value of team working and good team working practices (Tuckman 1965); Wagner 2004; Opie, 1997; Tunstall-Pedoe et al., 2003 and Pollard et al. 2004), however whether all groups can work effectively is a difficult question to answer and this can affect the extent of learning taking place. Ravenscroft (2005: 139) has argued: 'We

need to investigate, examine and where possible, design appropriate learning communities if we want to support effective e-learning discourse.'

\section{Evaluating the Evidence Which Exists to Support Claims of Professional Learning Through Virtual Simulation}

There is limited amount of literature examining the use of virtual simulations within legal education. Although the potential benefits that simulations could provide in legal education were noted over two decades ago (Widdison, Aikenhead, and Allen, 1997) legal education has been 'slow to discover that virtual simulation is a valuable method of learning about the law, the legal profession and its transactions' (Maharg 2004).

\subsection{Decision Making Skills}

The first computer simulation in law was designed to enhance students' decision-making skills. Degnan \& Haar (1970) undertook a literature review to assess potential learning and benefits from simulations. Their research was put to the test through an evaluation using 50 student questionnaires to ascertain simulation uses/advantages and found that simulation furnishes a method of relating specific legal questions to tasks requiring decision-making skill. However, no details of the questionnaire and method of scoring were provided to ascertain the validity of the findings. The next attempt by Widdison, Aikenhead and Allen (1997) consisted of a literature review where the authors argued that simulations could be used for legal analysis because of its artificial intelligence, although this has not been verified.

\subsection{Practical and Professional Skills}

In 2007, Maharg and Owen began a three-year project to place virtual simulations at the core of their curriculum development for a professional law course called Simulated Professional Learning Environment (SIMPLE). This was the biggest and most influential work on the use of virtual simulations in legal education to date. On this virtual simulation platform, students took on the role of a solicitor and worked in groups/firms. They were required to interact with various stakeholders within the virtual town, tackling a number of legal transactions such as conveyancing of property, drafting wills and personal injury claims. This gave students some experience of the work a solicitor would face in professional practice.

Evaluation on the effectiveness of the SIMPLE project was carried out between 2007-2010 using interviews, annual end-of-module student and staff feedback and student reflective reports. Maharg found that experiential learning is more effective than learning in any other formal academic setting. He contends that professional learning can only 
occur if the students actually go through the process of undertaking a transaction and ultimately enable more engaged and deeper learning. From their experience of designing and implementing virtual simulations in a law curriculum, research by Barton and Maharg (2006) suggest that simulations are effective tools for learning if designed well, mapped clearly with learning outcomes and centered around assessment and feedback. It is accepted that this is a valid assertion, one that helps to constructively align the learning, with the aims, outcomes and assessment of the subject area. However, the challenges of designing a virtual simulation using one or many of the theoretical frameworks discussed in the previous section still remains.

The feedback and interviews revealed that in working in collaboration, students realized the need for trust and mutual respect between team members and the value of community learning - aspects of professionalism that are rarely the subject of learning in conventional legal curriculum.

The students' reflective reports showed that they gained experience in practice-based ethics when pursuing or defending legal claims. Professional learning on matters such as the ethical protocols to follow at each stage of a transaction and in gathering and disclosing information relating to a client, realizing the values and attitudes to be a solicitor by interacting with characters and modelling themselves on their practitioner-tutors were applied into practice in transactions. Students' feedback also mentioned improvement with confidence which they felt was due to the use of the simulated method of learning.

However, feedback indicated that the level of student learning varied within the transactions. Not all students felt that they had actually developed further professional knowledge from engaging with the transactions (p.30). There were students who resisted the environment citing reason such as the virtual is inauthentic, dislike to simulated activities, or they find the process of group work problematic (p.31). Using the feedback, reflective reports and interview data, the project concluded that students' professional skills were enhanced; they developed a heightened awareness of client care and developed a fuller understanding and application of law (Gould, Hughes, McKellar, Maharg, Nicol, 2008, p30-31; 36-37). However, these contentions have not been sufficiently verified using pre-tests/post-tests and control groups to identify improvements or effectiveness in learning.

Due to the limited studies available in Law, examples of simulations in healthcare will be used to evaluate the type of learning and evidences necessary to ascertain its effectiveness. Within the context of healthcare education, in Seybert and Barton's (2007) study, students participated in practical sessions using a high fidelity virtual patient simulator. Before their participation on the virtual simulation, students undertook a written examination. After the participation on the simulation, students took another written examination on the same subject area. After participating on the simulation, there was a significant improvement in knowing and understanding. Evaluations from the pre/post simulation participation showed improvement in clinical skills. The findings in this study are deemed to be reliable because of the triangulation of data from pre/post examination, use of control groups as valid measure of learning outcomes (p.4).

Moule et al.,'s (2008) study investigated the clinical skills gained by 69 students who participated in a simulation. Student worked on five skill-related areas in healthcare related subject matter and was asked to complete pre-simulation and post-simulation multiple choice examinations. Students were also interviewed. The findings were satisfactorily triangulated and reliable. In this study, simulations were found to 'support the development of knowledge and skills in a range of clinical practice scenarios, offering opportunities for skill rehearsal, feedback and testing prior to consolidation in practice' (p.796).

\subsection{Problem Solving Skills}

To manage medical emergencies, a medium fidelity simulator was designed as a learning and training tool and tested on a number of students (Weller 2004). A subsequent questionnaire showed that students valued the simulation learning experience and the majority found that the collaborative team learning helpful. Less than half (11/33) thought that their problem solving skills had improved and were more capable of transferring their learning to an actual clinical setting. Around half of the students though that simulations such as the one used in the study should be used more often as part of the curriculum or should become a mandatory part of training. Only 5 students however commented on the authenticity of the experience whilst a further 5 valued learning and learning from mistakes within a safe and realistic setting.

In Mole and McLafferty's (2004) study a simulated ward was evaluated for its effectiveness as a learning and training tool. Here the researchers gathered 123 questionnaire responses from participants of the simulation experience. Students said that they felt more nervous in a simulated environment than in a ward situation because the environment was unfamiliar. 39\% agreed that they did not enjoy the 90 -minuite experience despite $86 \%$ agreeing that 
the exercise proved beneficial. No reliability or validity issues were reported.

Hogg et al. (2006) studied a simulated ward and later evaluated by six questionnaires and a focus group discussion. Considerable areas for improvement were suggested by the participants. Although the study concluded that the environment is safe and effective for training, participants identified that they were unsure of the performance level expected and that they had insufficient time to complete the tasks. Feedback also indicated improvements to the design and features on the platform and the need for more realistic exercises (Hogg et al., 2006, p. 222).

\subsection{Improved Knowledge and Understanding of Theoretical Principles}

Learning by way of a simulation has a number of strong benefits and opportunities. However, there is a need for effective and suitable transferability of learning and skills after participation in a simulated programme in order to create a meaningful learning experience. Baillie and Curzio's (2009) study involved a control group of 88 students who undertook a clinical placement, whilst 179 students undertook a simulated clinical programme. The study utilized objective tests and surveys to gather their findings. Students who undertook the simulation programme felt that their subject knowledge had improved, they felt confident and in fact they did not feel disadvantaged from not attending the clinical placement. Tests from the study indicate that there was no significant difference between the confidence of the simulation and control group, and as such the study concluded that the simulation programme was as effective as the clinical placement programme.

Another study examined the differences in students' learning after a clinical experience as opposed to a simulated experience. Hicks et al.'s study (2009) involved 58 undergraduates who were assigned to either simulation (30 hours), clinical (30 hours) or a combination of simulation and clinical (15 hours each). After this, the students undertook tests and focus groups to help determine the level of learning through each means of learning. The results showed that all three groups had significantly decreases their knowledge of the subject matter tested and the simulation only group appeared to retain the least level of knowledge. Further, in comparison with other groups, the simulation group was unable to perform to the required standard in the clinical tests. The study however showed that those who participated in the simulation only had developed a higher level of self-confidence than students in the clinical group, although insufficient evidence to determine problem solving, decision-making and psychomotor skills resulting in inconclusive findings (p.463).

\section{Future Use of Virtual Simulations in Legal Education}

The underlying motivation for exploring the use of virtual simulations is a call from the Carnegie Report (2007) for law schools to integrate 'student learning of theoretical and practical legal knowledge and professional identity' through the framework of experiential and activity learning to enable schools to transform a teaching culture into a professional learning culture.

This paper evaluated whether there are any evidences available to support the premise that virtual simulations can facilitate professional learning. Drawing upon the theoretical frameworks examined, mirroring the epistemological stance of constructivism, immersive learning encourages students to find their own voice and strengths so that they can understand and perform the practical and professional tasks (Barton \& Maharg 2005,p.115) whilst creating opportunities to prepare students for actual professional work. Students can become fully immersed within decision-making and problem solving creating deeper and critical understanding of new knowledge.

Further, this paper considered the value of a virtual/online simulation as a teaching and learning technique. It can be argued that there are many advantages to embedding virtual or online simulation and, one such is to adapt our teaching to prepare students for a modernized legal practice (Thanaraj \& Sales, 2015; Grech, 2013; Langan 2013). Technology has influenced the way legal services and many other professional services are beginning to be delivered, alongside the way in which interaction with clients and stakeholders and business takes place (Garon 2006; Legal Services Act 2007; The American Bar Association’s Commission on the Future of Legal Services 2014;).

Within the context of legal services, Susskind (2013, 2015), author of 'Tomorrow's Lawyers: An Introduction To Your Future' and 'The Future of the Professions' believes that law schools need to recognize the possible changes that IT and the Legal Services Act 2007 will have on the profession and prepare their students for a new future accordingly. Part of this preparation must involve exposing students to different methods of communication and interaction which involve contemporary and developing technologies. Virtual simulation can be designed to facilitate learning and experiencing the delivery of services online, and, this is the motivation behind the use of the VLC for training purposes, as set out in the research motivation section of this paper. 
The studies suggest that simulations create opportunity for social interaction between individuals and communities, creates personalized learning opportunities, a community presence and a sense of belonging within the simulation community, likely to lead to deep learning. Despite the optimism about the use of virtual simulations in learning, much of the evidence on its educational value is anecdotal and supportive by feedback from staff and students only. There is little by way of triangulated empirical evidence. The studies explored earlier show little evidence of how the learning gained from a virtual simulation can be transferred to actual professional work-based learning settings.

In particular, Shaw (2010) explains that many of the studies around virtual simulations are lacking rigor, particularly '...evaluations of the effectiveness of simulations were methodologically weak and flawed by research design, sampling, or other methodological problems'. Furthermore, in designing a simulation, its fidelity is a key component, yet, models of integration and models of design of simulations have not been explored in the studies.

Other unanswered questions in this review relating to using simulations as an educational tool include: Are simulations effective tools for decision-making, problem-solving, fact-gathering and communicating? How are knowledge and skills acquired and retained? How does a student's attitude change to bring about the professional learning and professional identity? Can simulation learning affect client care? What types and levels of competencies can simulations reliably and validly assess? Does good performance in a simulation reflect competency in real life client interaction? Can simulation be accepted by the Law Society as a method of assessment throughout the law curriculum?

\section{A Reflection on Designing a VLC Simulation as a Training Platform}

\subsection{Design of the Simulation}

- Identifying the potential barriers or restrictive aspects of the learning environment to be addressed opportunity for reflection, feedback, repeat practice, collaboration, trial and error practice, authentic activities and opportunities.

- $\quad$ Ensuring essential elements of the simulation environment must be realistic and provide a safe environment in which students can observe and practice

- Evaluating whether the simulation platform itself offers an authentic professional environment - with adequate opportunity to learn about the profession's activities through e-practice management software, time keeping, dealing with confidential data and handling client enquiries professionally and safely.

- Designing activities within the platform to enable authentic problem-solving of both substantive and procedural knowledge of legal transactions within a professional context

- $\quad$ Developing the design of activities around the intended learning outcomes

- Considering how the activities trigger responses in individuals, teams and follow-up actions, and the relationships between specific actions and the activity

- $\quad$ Embedding common practices of professional conduct can be introduced into the activities

- $\quad$ Creating an environment which is academically stimulating and challenging, one that is motivating to develop new learning and advanced thinking skills with feedback built into the activities

- $\quad$ Considering the role that the learner plays to ensure successful immersion, collaboration and interaction to facilitate learning

\subsection{Interaction and Learning within the Simulation}

- $\quad$ Creating learning with testing of knowledge and feedback built around the activities.

- $\quad$ Embedding opportunity to explore emotional and expressive authenticity as part of developing a sense of identity as a professional

- Embedding creativity, professional responsibility, decision-making and judgement skills into the activities to maximize deep learning.

- $\quad$ Creating opportunity to learn from errors

- Carefully embedded activities to raise awareness of ethical dilemmas and promote critical analysis of all the implications of their decision making.

- Embedding opportunities to reflect on tasks, actions taken and decisions made, allowing learning to be 
consolidated and application of knowledge to be refined and understood.

\section{Conclusion}

Simulations are a valuable method of learning. Its pedagogical premise is built around the learning opportunities it is capable of affording especially in its ability to allow application of tacit knowledge into a practical situation, whilst building upon that knowledge through new ways of doing. The review consulted demonstrates that simulations have been used for a long period of time, and has the potential of being designed to develop professional skills, knowledge of professional practice and professional identity. The review also outlined theoretical frameworks which provide a solid foundation for designing simulations, together with the associated challenges and issues faced in the design process. It is advocated that if designed well, with attention given to some of the reflections for improvement discussed in this paper, simulations are a cutting-edge learning and teaching technique to prepare students for professional careers.

\section{References}

Aldrich C. (2003). A field guide to educational simulations. American Society for Training and Development (ASTD). Retrieved from: http://www.simulearn.net/pdf/astd.pdf

Angehrn A. (2005). Learning to manage innovation and change through organizational and people dynamics eSimulations. Proceedings of the International Simulation \& Gaming Association Conference 2005, Retrieved from: http://www.calt.insead.edu/Publication/conference/2005-isaga-learning-tomanage- innovation.pdf

Armstrong K. (2003). Applications of role-playing in tourism management teaching: Evaluation of a learning method. Journal of Hospitality, Leisure, Sport and Tourism Education, 2(1), 5-16. https://doi.org/10.3794/johlste.21.24

Baillie, L., \& Curzio, J. (2009). Students' and facilitators' perceptions of simulation in practice learning. Nurse Education in Practice, 9, 297-306. https://doi.org/10.1016/j.nepr.2008.08.007

Barab, Squire \& Dueber. (2000). A co-evolutionary model for supporting the emergence of authenticity. Educational Technology Research and Development, 48(2), 37-62.

Barton, K., \& Maharg, P. (2006). Simulations in the wild: interdisciplinary research, design and implementation, in Games and Simulations in Online Learning, edited by Aldrich, C., Gibson, D., Prensky, M., Part 2, chapter 6, p.170-218, Idea Group Ltd, 115-148.

Barton, K., \& Westwood, F. (2006). From student to trainee practitioner - a study of team working as a learning experience. Web Journal of Current Legal Issues, special issue on Legal Education, edited by Spencer, M. Retrieved from: http://webjcli.ncl.ac.uk/2006/issue3/barton-westwood3.html

Barton, K., McKellar, P., \& Maharg, P. (2007). Authentic fictions: simulation, professionalism and legal learning, Clinical Law Review, 14(1), 143-93.

Biggs, W. (1990). Introduction to computerized business management simulations. In J.W. Gentry (Ed.), Guide to Business Gaming and Experiential Learning, pp. 23-35. New York: Nichols Publishing.

Black P., \& Wiliam D. (1998). Inside the black box: Raising standards through classroom assessment. London, UK: King's College London School of Education. https://doi.org/10.1038/35064

Brett-Fleegler M., Vinci R., Weiner D., Harris S., Shih M., \& Kleinman M. (2008). A simulator tool that assesses pediatric resident resuscitation competency. Pediatriatics, 121(3), 597-603. https://doi.org/10.1542/peds.2005-1259

Brown J., Collins A., \& Duguid P. (1989). Situated Cognition And The Culture Of Learning. Educational Researcher, 18(1), 32-42. https://doi.org/10.3102/0013189X018001032

Connolly, T., Boyle, E., MacArthur, E., Hainey, T., \& Boyle, J. M. (2012). A systematic literature review of empirical evidence on computer games and serious games. Computers \& Education, 59(2), 661-686. https://doi.org/10.1016/j.compedu.2012.03.004

Cooper D. (2005). 'Assessing What We Have Taught: The Challenges Faced with the Assessment of Oral Presentation Skills' (Paper presented at the 28th Higher Education Research and Development Society of Australasia Annual Conference, Sydney, 3-6 July 2005) 216. Retrieved from: http://www.herdsa.org.au/wp-content/uploads/conference/2005/papers/cooper.pdf 
Cunningham C., \& Alexander C. (2011). Developing Professional Judgment: Law School Innovations in Response to The Carnegie Foundation's Critique of American Legal Education, in The Ethics Project in Legal Education 2011. Retrieved from: http://law.gsu.edu/ccunningham/FLP/Alexander-LearningToBeLawyers.pdf

De Freitas S., \& Oliver M. (2006). How can exploratory learning with games and simulations within the curriculum be most effectively evaluated? Computers and Education, 46(3), 249-264. https://doi.org/10.1016/j.compedu.2005.11.007

Dewey, J. (1916). Democracy and education: an introduction to the philosophy of education. New York: Simon \& Schuster.

Egenfeldt-Nielsen S. (2006). Overview of research on the educational use of video games. Digital Kompetanse, 3(1), 184-213. https://doi.org/10.1023/A:1008648532192

Engeström Y. (1999). Expansive visiblization of work: An activity theoretical perspective. Computer Supported Cooperative Work, 8, 63-93. https://doi.org/10.1023/A:1008648532192

Faria, A., \& Wellington W. (2004). A survey of simulation game users, former users and never users. Simulation and Gaming, 35(2), 178-207. https://doi.org/10.1177/1046878104263543

Garrison D., \& Anderson T. (2003). E-learning in the 21st century: A framework for research and practice. Routledge Falmer: London. https://doi.org/10.4324/9780203166093

Gee J. (2003). What video games have to teach us about learning and literacy. ACM Computers in Entertainment, 1(1), 1-4. https://doi.org/10.1145/950566.950595

Glasersfeld E. (1995). Radical constructivism: A way of knowing and learning. London: Falmer Press.

Gunter G., Kenny R., \& Vick E. (2008). Taking educational games seriously: Using the RETAIN model to design endogenous fantasy into standalone educational games. Educational Technology Research and Development, 56(5-6), 511-537. https://doi.org/10.1007/s11423-007-9073-2

Hogg G., Pirie E., \& Kerr J. (2006). The use of simulated learning to promote safe blood transfusion practice. Nurse Education in Practice, 6(4), 214-223. https://doi.org/10.1016/j.nepr.2006.01.004

Johnson, D., \& Johnson F. (1997). Joining Together: Group Theory and Group Skills. Boston, MA.

Kolb A., \& Kolb D. (2005). Learning styles and learning spaces: Enhancing experiential learning in higher education. Academy of Management Learning and Education, 4(2), 193-212. https://doi.org/10.5465/AMLE.2005.17268566

Kolb D. (1984). Experiential learning: Experience as the source of learning and development. Englewood Cliffs, NJ: Prentice-Hall.

Lave J., \& Wenger E. (1991). Situated learning: Legitimate peripheral participation. Cambridge University Press, Cambridge: UK. https://doi.org/10.1017/CBO9780511815355

Lean J., Moizer J., Towler M., \& Abbey C. (2006). Simulations and games: Use and barriers in higher education. Active Learning in Higher Education, 7(3), 227-242. https://doi.org/10.1177/1469787406069056

Legal Services Consumer Panel in November 2014 on '2020 Legal Services: How regulators should prepare for the future'. $\quad$ Retrieved from http://www.legalservicesconsumerpanel.org.uk/publications/research_and_reports/documents/2020consumercha llenge.pdf

Leont'ev A. (1978). Activity, consciousness, and personality. Englewood Cliffs: Prentice Hall.

Leont'ev A. (1981). Problems of the development of the mind. Moscow: Progress Publishers.

Maharg P. (2002). Transactional Legal Learning on the Web. Legal Information Management, 2(3), 26-33. https://doi.org/10.1017/S1472669600001201

Maharg P. (2001). Negotiating the Web: Legal Skills Learning in a Virtual Community. International Review of Law Computers \& Technology, 15(3), 345-360. https://doi.org/10.1080/13600860220108139

Maharg P. (2004). Legal Sims: From Everquest to Ardcalloch (and Back Again). CALI Conference, Seattle, 17-19 Retrieved June 2004 from http://www.caliauthor.net/conference/2004/presentations/Legal\%20Sims.doc

Maharg, P. (2007). Transforming Legal Education. Learning and Teaching the Law in the Early 21st Century. Aldershot, Ashgate Publishing. 
Maharg, Paul. (2006). On the edge: ICT and the transformation of professional Legal education. Web Journal of Current Legal Issues, 3. Retrieved from: http://webjcli.ncl.ac.uk/2006/issue3/maharg3.html

Marhag P., \& Owen M. (2007). E-Simulations, learning and the metaverse: changing cultures in legal education. Journal of Information Law and Technology. Retrieved from http://www2.warwick.ac.uk/fac/soc/law/elj/jilt/2007_1/maharg_owen/\#sdfootnote3sym

Mitchell, A., \& Savill-Smith, C. (2004). The use of computer and video games for learning: A review of literature. London: Learning and Skills Development Agency.

Mole L., \& McLafferty L. (2004). Evaluation a simulated ward exercise for third year student nurses. Nurse Education in Practice, 4, 91-99. https://doi.org/10.1016/S1471-5953(03)00031-3

Moss M. (2005). Personalized learning: A failure to collaborate? In S. de Freitas \& C. Yapp (Eds.), Personalising learning in the 21st century. Stafford: Network Continuum Press.

Moule P., Wilford A., Sales R., \& Lockyer L. (2008). Student experiences and mentor views of the use of simulation for learning. Nurse Education Today, 28(7), 790-797. https://doi.org/10.1016/j.nedt.2008.03.007

Opie, A. (1997). Teams as Author: Narrative and Knowledge Creation in case Discussions in Multi-Disciplinary Health Teams. Sociological Research Online, 2(3), 5.

Pollard, K. (2011). Interprofessional working and public involvement in research. In: International Health Forum, Faculty of Health Sciences, University of Ljubljana, Ljubljana, Slovenia. Retrieved 25th May 2011 from http://eprints.uwe.ac.uk/15613

Schroeder R. (1996). Possible Worlds: The Social Dynamic of Virtual Reality Technologies. Boulder: Westview Press.

Seybert A., \& Barton C. (2007). Simulation-based learning to teach blood pressure assessment to doctor of pharmacy students. American Journal of Pharmaceutical Education, 71(3), 48-54. https://doi.org/10.5688/aj710348

Sullivan, Colby, Wegner, Bond, \& Shulman. (2007). Educating Lawyers: Preparation for the profession of law. The Carneige Foundation for the advancement of teaching. Retrieved from http://archive.carnegiefoundation.org/pdfs/elibrary/elibrary_pdf_632.pdf

Tanner, C.A. (1987). Teaching Clinical Judgement. In: Fitzpatrick, J., Taunton, R.L., (Eds.), Annual Review of Nursing Research, 5, 153-173.

Thanaraj \& Sales. (2015). Lawyering in a Digital Age: A practice report introducing the virtual law clinic at Cumbria. International Journal of Clinical Legal Education, 22(3), 312-333.

The ABA's Commission on the Future of Legal Services, 'The Future of Legal Services: Changes and Challenges in the Delivery of Legal Services' State Bar of Michigan. Retrieved November 10, 2014 from http://www.michbar.org/file/generalinfo/pdfs/FutureReport.pdf

Tonks D. (2002). Using Marketing Simulations for Teaching and Learning: Reflections on an Evolution. Active Learning in Higher Education, 3, 177-194. https://doi.org/10.1177/1469787402003002006

Tuckman, B. (1965). Developmental Sequence in Small Groups. Psychological Bulletin, 63, 384-389. https://doi.org/10.1037/h0022100

Tunstall- Pedoe et al. (2003). Student attitudes to undergraduate interprofessional education. Journal of Interprofessional Care, 17(2), 161-172.

Vygotsky L. (1978). Mind in Society: The Development of Higher Psychological Processes. MA: Harvard University Press.

Wagner EH. (2004). Effective teamwork and quality of care. Med Care, 42(11), 1037-9. https://doi.org/10.1097/01.mlr.0000145875.60036.ed

Warburton S. (2009). Second in higher education: Assessing potential for and the barriers to deploying virtual worlds in learning and teaching. British Journal of Educational Technology, 40(3), 414-426. https://doi.org/10.1111/j.1467-8535.2009.00952.x

Webb, J. (2008). The dynamics of professionalism: The moral economy of English legal practice - and some lessons for New Zealand? Waikato Law Review, 16, 21-45.

Weller J. (2004). Simulation in undergraduate medical education: bridging the gap between theory and practice. 
Medical Education, 38(1), 32-38. https://doi.org/10.1111/j.1365-2923.2004.01739.x

Wenger E. (1998). Communities of practice. Learning, meaning and identity. Cambridge: Cambridge University Press. https://doi.org/10.1017/CBO9780511803932

Widdison, Aikenhead \& Allen. (1997). Computer simulation in legal education. International Journal of Law and Information Technology, 5(3), 279-307. https://doi.org/10.1093/ijlit/5.3.279 